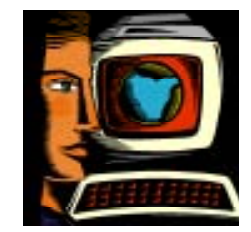

Eye on

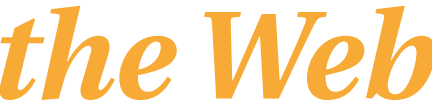

LINKS TO THE RESOURCES ON THE INTERNET

\title{
Intellectual Property Resources
}

Ah, to make accessible the results of human creative thought... what's a librarian not to love?

This article examines intellectual property resources made available via the Web sites of the Canadian Intellectual Property Office, the United States Patent and Trademark Office, the US Copyright Office and the World Intellectual Property Organization. Intellectual property (IP) is the legal term for property (which may be intangible) that is the product of creativity and invention. Legislation in many countries protects the products of intellectual activity in the arts, industry, literature, and the sciences by giving IP owners certain legal entitlements. These entitlements vary, depending on the type of IP that was created. Categories include copyright, industrial design, integrated circuit topography, patents, plant breeders' rights and trademarks. Generally speaking, copyright applies to the production or reproduction of all original literary, dramatic, musical, and artistic works. Industrial design refers to the visual features of a manufactured item. Canada's newest form of IP, the integrated circuit topography, protects the three-dimensional configuration of layers found on "microchips." Patents are issued for new inventions or processes, while trademarks distinguish products or services by using words, symbols and/or designs. Finally, plant breeders' rights apply to certain new plant varieties.

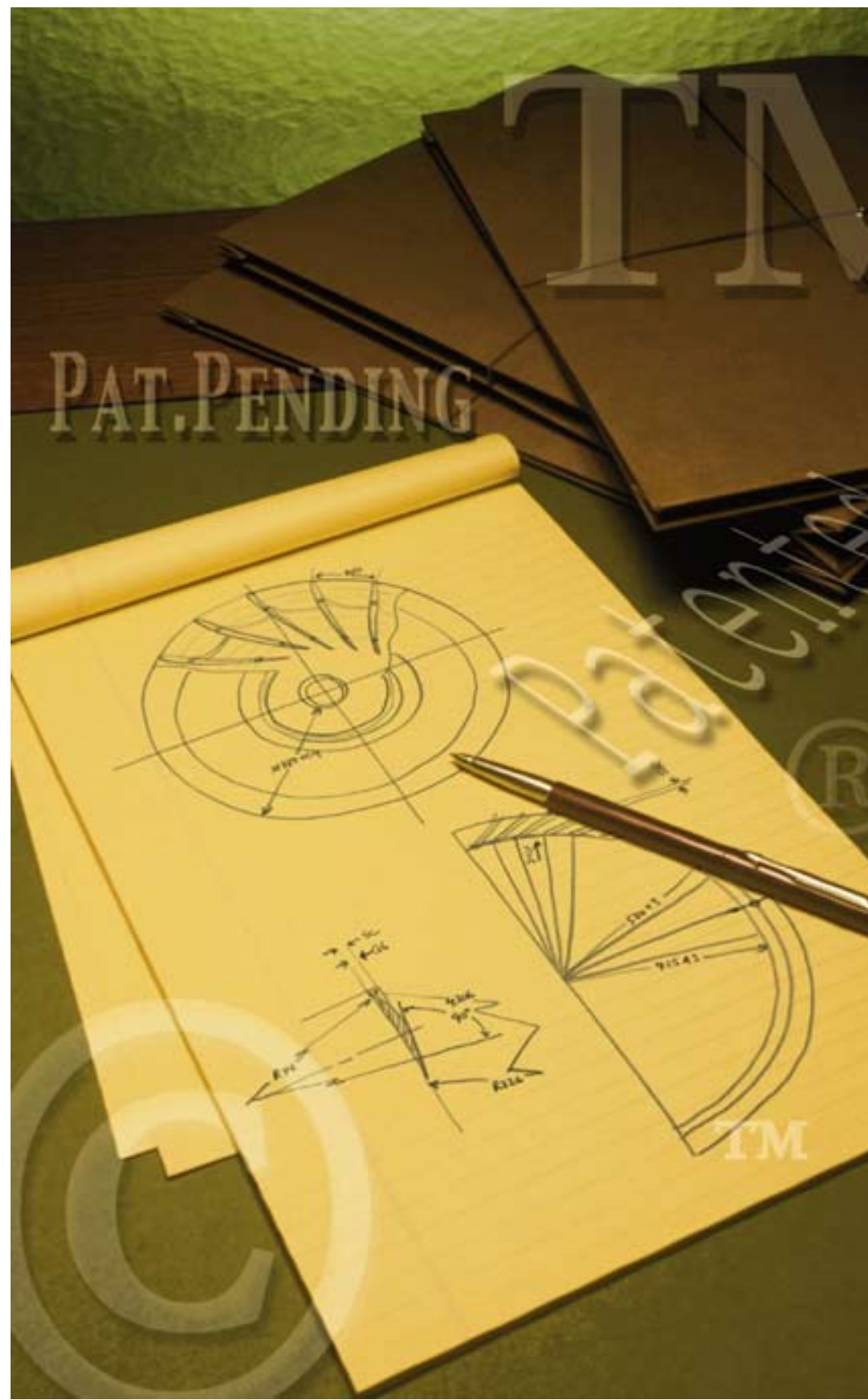

Canadian Intellectual Property Office (CIPO) http://cipo.gc.ca

CIPO is a special operating agency associated with Industry Canada. It is responsible for administering the intellectual property systems in Canada. This includes maintaining a Web site that provides access to copyright, industrial design, patent, and trademark databases - all of which are clearly linked on the left navigation panel of the homepage, include useful help screens, and provide images of the IP instruments when relevant. 
This Web site also provides access to online forms and general information about IP.

The Copyrights Database contains information about all copyrights registered in Canada under the Copyright Act after October 1, 1991. It also includes information about some pre-1991 copyrights following a request for a certified copy. The database is updated daily, and offers both quick searching, including a field browsing option and keyword searching that supports the use of Boolean operators.

The Industrial Design Database includes approximately 10,000 designs registered on or after June 15,2002 . It does not include images of assignment documents or pre-2002 registrations. The database is updated weekly and allows for searching by design or status. We are looking forward to the completion of a project to digitize documents dating from December, 1861, to June, 2002.

CIPO's Patents Database contains patents granted from 1920 to the present. Time delays for database updates vary: patents filed directly with the office are available within one week of the 'open to public inspection date'; Patent Cooperation Treaty applications are delayed five to nine weeks; old patent information is normally updated within two to four weeks. Since not all parts of the patent application are required at the time that the patent is being filed, there may be information and images missing. This database offers four search options: basic, number, Boolean and advanced. Note that the Library and Archives

Other Organizations Working with Intellectual Property Centre for Intellectual Property Policy http://www.cipp.mcgill.ca/en/

Creative Commons http://www.creativecommons.org/

International Chamber of Commerce <http://www.iccwbo.org>

International Confederation of Music Publishers <http://www.icmp-ciem.org>

International Federation of Reproduction Rights Organizations <http://www.ifrro.org>

International Trademark Association < http://www.inta.org>

International Council of Societies of industrial design <http://www.icsid.org>

IP Justice http://www.ipjustice.org/

Public Knowledge http://www.publicknowledge.org/
The USPTO trademarks database is without a doubt, the most multifaceted but the least user-friendly search tool discussed in this article. It offers a dizzying array of help features supporting access through five search interfaces: basic, Boolean, advanced, browse, publication and registration date.

\section{United States Copyright Office}

http://www.copyright.gov/

The US Copyright Office is a unit of the Library of Congress. It maintains a searchable database of copyright records dating back to 1978. The database provides separate access points for searching serials, ownership documents and all other types of registrations and renewals. Expect delays of a few months before new registrations are available for searching.

\section{World Intellectual Property Organization (WIPO)}

http://www.wipo.int

WIPO deserves a nod for creativity, defining IP as "works of the human spirit." This specialized agency of the United Nations is based in Geneva, and administers 23 international treaties for 183 member nations dealing with different aspects of intellectual property protection. Its activity areas include developing international standards for IP law and supporting developing countries in part, by disseminating information about IP. Thus, the WIPO Web site is a good starting point for those interested in international IP activities. The "News and Information Resources" link from the homepage provides access to searchable databases containing IP legislation, registrations (via the IP Digital Library), statistics, WIPO publications and meeting documents. This section of the Web site is also home to a directory of IP offices around the world.

Marcia Salmon is a Cataloguing Librarian, Bibliographic Services, Scott Library, York University,msalmon@yorku.ca.

Amanda Wakaruk is a Reference and Government Information Librarian, Scott Library Reference Department, York University,awakaruk@yorku.ca. 